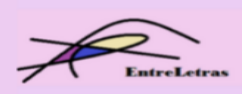

REVISTA ENTRELETRAS (ARAGUAÍNA), V. 12, N. 3, SET./DEZ. 2021 (ISSN 2179-3948 - ONLINE)

\title{
O ROMANCE HISTÓRICO NO CONTEXTO DA NOVA NARRATIVA LATINO- AMERICANA: \\ VEREDAS PARA A DESCOLONIZAÇÃO DA HISTÓRIA PELA FICÇÃO
}

\author{
THE HISTORICAL NOVEL IN THE CONTEXT OF THE NEW LATIN AMERICAN \\ NARRATIVE: PATHS FOR DECOLONIZATION OF HISTORY BY FICTION
}

DOI 10.20873/uft2179-3948.2021v12n3p333-347

\author{
Ana Maria Klock ${ }^{1}$
}

Resumo: Neste artigo perpassamos as veredas trilhadas pela literatura hispano-americana na sua trajetória de enfrentamento às versões eurocêntricas e o alcance dessas transformações na produção escritural recente. É nosso intento, dentro desse escopo, recuperar como tal processo dá-se a partir de adaptações efetuadas na nova narrativa hispano-americana após os engendramentos do boom, com ênfase ao romance híbrido de história e ficção, gênero que bem ilustra esse caminho de transformações e inovações no âmbito literário em nosso continente. Sob o intuito de contemplar como o romance híbrido sustenta, nas manifestações recentes do gênero, intenções críticas frente ao discurso eurocêntrico colonizador, tomamos para a análise expressões pertencentes ao eixo temático do "descobrimento" da América, demonstrando, a partir disso, que as narrativas, embora relativizando os pressupostos experimentalistas formais e linguísticos herdados do período do boom, mantêm assinalado o caráter altamente crítico em relação a como releem a história.

Palavras-chave: Modernismo hispano-americano. Nova narrativa latino-americana. Romance histórico.

Abstract : In this article we go through the paths taken by Hispanic American literature in its trajectory of confronting Eurocentric versions and the scope of these transformations in recent writing production. It is our intention, within this scope, to recover how this process occurs from adaptations made in the new Hispanic American narrative after the engendering of the boom, with emphasis on the hybrid novel of history and fiction, a genre that illustrates this path of transformations and innovations in the literary sphere in our continent. In order to contemplate how the hybrid novel sustains, in the recent manifestations of the genre, critical intentions against the colonizing Eurocentric discourse, we have taken for analysis expressions belonging to the thematic axis of the "discovery" of America, demonstrating that the narratives, although relativizing the formal and linguistic experimentalist assumptions inherited from the boom period, maintain a highly critical view in relation to how they reread History.

Keywords: Hispanic American Modernism. New Latin American Narrative. Historical Novel.

\footnotetext{
${ }^{1}$ Doutora em Letras pela Universidade Estadual do Oeste do Paraná (UNIOESTE); docente na Rede estadual de ensino do Paraná. E-mail: anamariaklock@ hotmail.com. Orcid: https://orcid.org/0000-0001-9925-3857.
} 


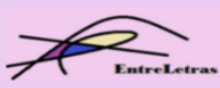

REVISTA ENTRELETRAS (ARAGUAÍNA), V. 12, N. 3, SET./DEZ. 2021 (ISSN 2179-3948 - ONLINE)

\section{Introdução}

Vemos, pois, que, desde meados do século passado até o presente, a escrita do romance histórico experimenta, no cenário literário latino-americano, um desenvolvimento extraordinário, evolução acompanhada por inovações técnicas e estilísticas e pela liberdade de manejo do material histórico pelo romancista, aspectos que estabeleceram transformações profundas nesse gênero nascido em solo europeu.

Como expressão literária que se alimenta de aspectos do tempo pretérito registrado, tomando-o como recurso estético e valor simbólico para assimilá-lo sob diferentes intenções e modos, a narrativa híbrida de história e ficção constitui-se como via privilegiada para oferecer leituras outras da história, confrontando diretamente perspectivas unívocas, valores, imaginários, simbologias, mitos, conjunturas e feitos. Por ser espaço lúdico de liberdade criadora e inventiva, oferece ainda distintas possibilidades de resgate e revisitação de acontecimentos e personagens do passado, discurso poético crítico que se traduz em arte e acrescenta novos entendimentos sobre os referentes que ficcionaliza.

A culminância do gênero como tendência recorrente na produção narrativa contemporânea, fator sustentado pela incidência do grande número de romances históricos lançados no mercado editorial a cada ano, é efeito de um longo processo de renovação da literatura latino-americana.

Nossa abordagem a esse gênero literário por meio de um passeio pela história da literatura latino-americana tem como intuito maior o de contextualizar ao leitor em que momento a América Hispânica, em especial, descobre o potencial revisionista crítico que o gênero romance histórico poderia oferecer para o tipo de história que se vivenciou no nosso continente e como isso se coloca atualmente. Do contexto em que o gênero ainda era voltado à exaltação de ações e sujeitos do passado, característica da primeira fase acrítica do gênero, vemos que o romance histórico converteu-se, e assim segue, como um importante leitor da nossa história.

Por meio de uma revisitação às contingências histórico-literárias da América Latina do final do século XIX à contemporaneidade, a literatura latino-americana, após perpassar um período de rupturas dos modelos e parâmetros eurocêntricos aqui introduzidos pelas metrópoles colonizadoras - momento conhecido com Modernismo hispano-americano -, passou a produzir uma literatura extremamente experimentalista e desafiadora, instaurada pela nova narrativa (1940) e evidenciada, no seu clímax, durante o boom (1960-1970). 


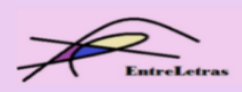

REVISTA ENTRELETRAS (ARAGUAÍNA), V. 12, N. 3, SET./DEZ. 2021 (ISSN 2179-3948 - ONLINE)

Em reação a essas obras "[...] excesivamente literárias", como alude Jose Donoso (1987, p. 99) em relação à complexidade praticada pelos romancistas, segue, posteriormente, o fenômeno do pós-boom no qual é reivindicada uma escrita menos experimentalista e, portanto, mais acessível a um público mais amplo, que relativiza as atitudes escriturais e os procedimentos teóricos mais exacerbados pelos escritores, aproximando-se, assim, daqueles leitores menos especializados.

Frente a essas transformações no âmbito global da literatura produzida no contexto hispano-americano, nossa abordagem nesse artigo visa igualmente perpassar esses diferentes momentos de transformações e renovações, porém para evidenciar, dentro disso, como o romance histórico constitui-se como uma das possíveis vias de descolonização do pensamento, ainda que, na atualidade, com obras menos desconstrucionistas e experimentalistas que aquelas produções altamente complexas do auge do boom, dentro deste gênero, nas décadas entre 1940 e 1980.

\section{Do Modernismo ao boom: a maturidade da nova narrativa latino-americana}

Uma das mais representativas contribuições à literatura latino-americana no final do século XIX com alcance sobre o XX, foi, notoriamente, o Modernismo hispano-americano, principiado por José Martí em Cuba e consolidado pelo nicaraguense Rubén Darío. Primeiro movimento intelectual, ideológico e artístico hispano-americano, de origem e características próprias a surgir nessas terras - e que, até mesmo, se antecipou às inovações estéticas na Europa, deixando, inclusive, sua influência sobre ela -, tem o impacto da sua transformação rastreado até à contemporaneidade, integrando-se, inevitavelmente, às demandas com vistas à descolonização.

Desde a longa fundação de nossa literatura sobre os moldes europeus, vemos assentadas no momento culminante do Modernismo (1875-1920) acirradas reações a esse domínio, resultando, justamente, nas rupturas com os ditames literários eurocêntricos dominantes na América até então e cuja premissa é sustentada, mesmo hoje, ainda que, como veremos, “[...] como actitud vital bajo diversas formas evolucionadas" (SCHULMAN, 1969, p. 11).

Esse momento da história da literatura latino-americana é exemplar como fenômeno que é, ao mesmo tempo, contraditório, multifacetado, e não só, necessariamente, literário, mas com alcance social e cultural. Sob o entendimento desse amplo conceito, porém pensando nos termos da arte literária, os escritores modernistas não rechaçaram nem incorporaram em sua totalidade as tendências literárias - Romantismo, Parnasianismo, Simbolismo - e filosóficas - 


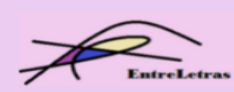

REVISTA ENTRELETRAS (ARAGUAÍNA), V. 12, N. 3, SET./DEZ. 2021 (ISSN 2179-3948 - ONLINE)

Positivismo, Evolucionismo, Hegelianismo - europeias do século XIX, porém apropriaram-se delas segundo seu ímpeto criativo, desimpedidos para, dentro da orientação do movimento, isto é, do experimentalismo e da estética livre, encontrar sua via de expressão própria.

Como capítulo primeiro de um fenômeno que se desdobrará, sob diferentes orientações, ao final do século XIX e início do século XX, com reflexo, em parte, na Literatura Brasileira décadas mais tarde (com nomes como Graciliano Ramos, José Lins do Rego, Jorge Amado, João Guimarães Rosa), integram o Modernismo hispano-americano escritores nos quais foi reconhecida uma nova atitude escritural e que adotaram uma nova estética, forma de expressão que se distanciou cada vez mais daquela vinda da metrópole. Embora o cenário literário hispano-americano já contasse, no século XIX, com o nome de grandes romancistas, o que ocorre é que, conforme explica Rodríguez Monegal (1968, p. 49), “[...] no se puede decir que haya realmente novela (es decir: un género completo, con autores de muchos niveles y una producción sostenida) hasta este siglo. Pero sólo hay novela, en el sentido más profesional de la palabra, a partir de ese 1940.”.

A maturidade das transformações empreendidas pelo Modernismo hispano-americano, ou dito de outro modo, da conquista do espaço do escritor latino-americano - inserido naquilo que Santiago (2000) chama de entre-lugar -, são plenamente exploradas, a partir de então de forma fermental, nas décadas de 1930 e 1940. Essa renovação da prosa é reunida sob a expressão nueva narrativa latino-americana, cujo momento clímax ocorre no fenômeno denominado pela onomatopeia boom, nas décadas de 1960 e 1970, processo que resultou na constituição de um sistema literário mais autônomo e reconhecido mundialmente, vinculado ao Modernismo hispano-americano.

Esses dois fenômenos - o da nova narrativa latino-americana e o do boom - podem ser entendidos nos seguintes termos, conforme estabelece De la Fuente:

El término Nueva Novela - extensible a la narración corta - se refiere a una particular reacción, producida desde los años cuarenta, contra los presupuestos narrativos y las formas de la novela realista tradicional, que se centraba en los problemas sociales de Hispanoamérica, la situación del medio rural o la marginación sufrida por ciertos grupos, lo que se reducía habitualmente a una solución novelesca excesivamente simplista y maniquea. Esta distorsión de la auténtica realidad era aceptada por los lectores, acostumbrados a asumir esos presupuestos como ciertos, a lo que contribuía el punto de vista desde el que se situaba el narrador omnisciente que relataba la historia desde la tercera persona. El término Boom supone una explosión de la actividad literaria y el éxito editorial en los años sesenta de las narraciones y narradores hispanoamericanos. (DE LA FUENTE, 1996, p. 13) 


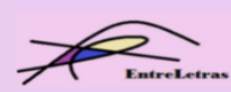

REVISTA ENTRELETRAS (ARAGUAÍNA), V. 12, N. 3, SET./DEZ. 2021 (ISSN 2179-3948 - ONLINE)

O boom, em linhas gerais, foi um momento em que o público leitor voltou-se ao sistema literário latino-americano interessado na heterogênea produção escritural e notadamente marcada pelo rigor estético que alimentou, pelo ângulo econômico, o êxito do mercado editorial interno, levando à internacionalização das letras americanas. A combinação desses fatores mercado editorial, criação artística, público leitor - resultou, no decurso de uma década, entre 1960 e 1970, na massiva divulgação e internacionalização dos produtos literários aqui produzidos, convencionalmente chamado de boom da literatura latino-americana, "[...] un fenómeno específicamente latinoamericano de preferencia hispanoamericana [...] que se caracteriza por rupturas con la tradición literaria y con hábitos de lectura" (POLLMAN, 1989, p. 78).

Esse contexto da literatura latino-americana, conforme argumenta Fleck (2017, p. 58), caracteriza-se fundamentalmente por dois aspectos que foram exacerbados no boom: o experimentalismo linguístico e o experimentalismo formal praticado pelos romancistas e cujas inovações estão também presentes no gênero romance histórico. Tais transformações contribuem por suplantar a visão da literatura latino-americana como cópia e dividendo do cânone europeu a partir desse " [...] proceso que se alimenta por igual del estímulo (negativo y positivo) del extranjero y de un enraizarse en la realidad, en la conciencia, en la misión de América Latina" (RODRÍGUEZ MONEGAL, 1968, p. 49-50).

Nessa renovação linguística e formal instituída pela nova narrativa latino-americana encontram-se também envoltas as escritas híbridas de história e ficção, sobre as quais trataremos na seção a seguir.

\section{O romance histórico no contexto da nova narrativa latino-americana: a fase crítica/desconstrucionista do gênero}

Segundo sustenta Fleck (2017), o romance histórico latino-americano inaugura a segunda fase de produções no gênero que por suas distintas marcas rompe tanto com a matriz fixada por Scott, no século XIX, quanto com as primeiras inovações nela estabelecidas ao longo do Romantismo e do Realismo/Naturalismo. Conforme expressa o crítico, as narrativas híbridas que surgiram a partir da década de 1940 na América Hispânica abandonam a acriticidade da primeira fase de produções do romance histórico - na qual se destacam as modalidades clássica scottiana e a tradicional praticadas em solo europeu.

Nas obras de caráter renovador identifica-se a impossibilidade de captar a factualidade histórica ou a "realidade" do tempo pretérito; de admitir uma concepção de tempo cíclica e, 


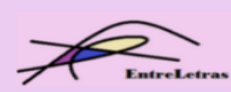

REVISTA ENTRELETRAS (ARAGUAÍNA), V. 12, N. 3, SET./DEZ. 2021 (ISSN 2179-3948 - ONLINE)

portanto, imprevisível quanto ao seu desfecho ou resultado; o uso de estratégias que justamente distorcem o tempo, efeito alcançado pelos anacronismos e comentários sobre o processo de composição; a presença da intertextualidade em diferentes níveis, evidente por meio de fenômenos como a dialogia, a paródia, a heteroglossia e a carnavalização; e uma forte predileção por ficcionalizar personagens históricas conhecidas pelo público a fim de desestabilizá-las ou desmitificá-las. O que reúne essas obras sob um mesmo teto é a proposta de oferecer nelas ressignificações críticas/desconstrucionistas das versões tradicionais do passado pela história na ficção.

As características da nueva novela histórica latinoamericana - nomenclatura emprestada da nueva narrativa por também renovar as características do gênero híbrido - foram instituídas, segundo o entendimento de Menton (1993), partindo dos estudos de Aínsa (1988; 1991), por Alejo Carpentier, em 1949, com a obra El reino de este mundo, angariando já nos anos seguintes nomes de relevo, como os de Carlos Fuentes e Augusto Roa Bastos, na década de 1970. Nesse cenário, portanto, Carpentier tem papel fundamental como difusor da modalidade do novo romance histórico latino-americano, em que antecipa ao leitor um universo de inovações e experimentalismos dentro da narrativa híbrida de história e ficção que se consolidará nas décadas seguintes.

Conforme o estudo da obra, apresentado por Tonet (2018), El reino de este mundo (1949) rompe com a tradição canônica no que concerne às escritas híbridas de história e ficção que manifestavam as características das modalidades clássica e tradicional de origem europeia. A ruptura que se estabelece por meio da projeção dessa obra ocorre, a exemplo das demais narrativas inovadoras da fase de implementação da nova narrativa latino-americana, na forma do romance, isto é, pelo experimentalismo formal, ao corromper as formas espaciais e temporais; e pelo experimentalismo linguístico, que submete a variante canônica a uma série de deformações no qual prevalece o barroquismo que, conforme analisa Fleck (2017, p. 58), também divide espaço com traços da oralidade, oriundos das ancestrais civilizações précolombianas e das comunidades africanas e afrodescendentes do Haiti.

O intento do romancista em dar corpo e forma, no discurso poético, a esse expressivo panorama histórico-cultural, por meio do mergulho no real maravilhoso, faz com que trabalhe nas lacunas da história, explorando-as das mais diversas maneiras para compor uma representação do passado a partir das fronteiras entre o ocorrido, o imaginário e o lendário.

É em razão dessa proposta de leitura ficcional que se motiva a contestação da visão do colonizador e o fato de revisitar o passado por olhares não privilegiados pelo discurso 


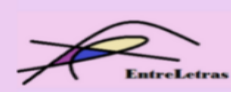

REVISTA ENTRELETRAS (ARAGUAÍNA), V. 12, N. 3, SET./DEZ. 2021 (ISSN 2179-3948 - ONLINE)

historiográfico hegemônico. São esses procedimentos estéticos que ressignificam o material histórico inserido na tessitura da obra e inauguram uma nova fase nas escritas híbridas de história e ficção na América Latina, segundo afirma Fleck (2017) e que, daqui, expandiu-se para outras sociedades.

A incorporação no tecido narrativo dessa peculiaridade da existência latinoamericana foi, pois, projeto estético de muitas das ações de implementação da nova narrativa latinoamericana que, nesse particular, diferenciou-se das literaturas canônicas europeias por apresentar uma nova visão de mundo que fascina, até os dias de hoje, aqueles que nela não estão integrados.

É necessário salientar, contudo, que estudos mais recentes, como feito por Mendez (2021), apontam que Mi Simón Bolívar (1930), do colombiano Fernando González Ochoa, é o romance que estabelece, no século XX, na América Latina, a ruptura com as modalidades acríticas precedentes, sendo, assim, obra precursora das modalidades críticas do gênero em nosso contexto do século XX.

O tratamento literário dado à personagem histórica na ficção fundamenta-se no processo de humanização. Isto é, o rebaixamento da figura de Simón Bolívar a partir da organização da linguagem e dos acontecimentos que receberam destaque na história oficializada do continente. De tal forma, o primeiro grande passo do literato colombiano foi desmontar a figura do "Libertador", retirando-a do seu pedestal, oportunizando, assim, novas veredas de análise para os fatos relatados de sua vida e seus feitos a partir das ressignificações possíveis à ficção.

Partindo dessa publicação de Ochoa, que pode ser tomada como precursora, e a de Carpentier, como aquela que institui os parâmetros da modalidade crítica/desconstrucionista, vemos que a escrita das modalidades do novo romance histórico latino-americano e da metaficção historiográfica, integrantes dessa fase, ainda seguem publicadas e presentes na contemporaneidade, contrariamente ao que parece à modalidade acrítica scottiana .

Embora essas produções possam ser agrupadas, conforme as características que expressam, há, contudo, algumas exceções que merecem ser citadas. É o caso do primeiro romance histórico latino-americano, Xicotencátl (1826), de autoria anônima, e de Cinq Mars (1826), do francês Alfred de Vigny. Estas obras apresentam um teor crítico incomum para a época de sua produção, o ano de 1826, pois, nele, imperavam as obras clássicas que seguiam à risca os parâmetros scottianos de produção do gênero híbrido.

Essas duas obras, portanto, destoam em relação à estrutura do romance histórico em voga na época e, em especial, em sua postura ideológica crítica frente aos eventos passados 


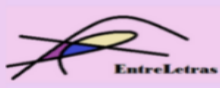

REVISTA ENTRELETRAS (ARAGUAÍNA), V. 12, N. 3, SET./DEZ. 2021 (ISSN 2179-3948 - ONLINE)

recriados em seu entrecho. Elas não podem, assim, ser classificadas na modalidade existente à época: a clássica scottiana, único paradigma do gênero que era imitado, traduzido e copiado ao redor do mundo até a data dessas publicações, em 1826. A quebra de paradigmas que se opera nessas duas produções pode ser vista, embora não necessariamente, como um caminho aberto às alterações que começaram a surgir ainda na época do Romantismo na produção híbrida de história e ficção que passou, gradativamente, a alterar as características predominantes da escrita scottiana inicial.

Tal como apontado anteriormente, Xicoténcatl (1826) é o primeiro romance histórico latino-americano escrito em língua espanhola que, mesmo publicado na Filadélfia, integra o conjunto da produção romântica da literatura mexicana, como desenvolve a pesquisadora Del Pozo González (2017, p. 11) em relação à inserção dessa obra no cenário literário hispanoamericano. Apesar das expressões literárias latino-americanas dessa época ainda estarem condicionadas ao cânone europeu, essa obra mista de história e ficção apresenta rupturas com o modelo clássico de Scott reinante na época por ser uma tentativa bem-sucedida de analisar criticamente a posição da América Latina no cenário das recentes nações americanas independentes e das lutas por elas naquelas que ainda não a tinham alcançado, como é o caso do México à época da publicação de Xicoténcatl (1826).

Para esse propósito, a narrativa anônima usa, deliberadamente, o contexto da queda do Império Asteca, impulsionada pelas ações do conquistador espanhol Hernán Cortés. O narrador estradiegético de Xicoténcatl (1826) - que, como era normal na época, enuncia em voz heterodiegética - explora o lado sombrio e a decadência moral do herói da Contrarreforma espanhola, ao mesmo tempo em que concentra a atenção em uma personagem autóctone, o jovem Xicoténcatl, figura histórica descrita pelos registros oficiais como um vilão em oposição aos planos do conquistador espanhol.

Prevalece, na obra romântica latino-americana, uma clara oposição entre a imagem do colonizador e a do colonizado, na qual é empregada uma perspectiva inédita no gênero romance histórico da época: inverte-se o discurso da conquista do México pelo foco narrativo adotado, em que os autóctones ocupam lugar de protagonismo na diegese e aparecem no papel de heróis, exaltados e referenciados por suas qualidades e virtudes; já os conquistadores espanhóis, heróis eleitos pela história positivista eurocêntrica, figuram no discurso ficcional como antagonistas e são duramente criticados e denunciados pelos abusos e pela violência perpetrada ao longo de toda a conquista, visão explorada na narrativa sob uma perspectiva que valoriza a resistência autóctone frente às muito superiores forças bélicas espanholas. 


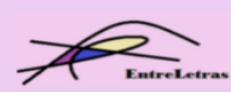

REVISTA ENTRELETRAS (ARAGUAÍNA), V. 12, N. 3, SET./DEZ. 2021 (ISSN 2179-3948 - ONLINE)

Da mesma forma que Del Pozo González (2017), Fleck (2017), ao tratar da trajetória do romance histórico na América Latina, argumenta que Xicoténcatl representa, pela sua perspectiva crítica, uma ruptura com a modalidade europeia dominante no Romantismo e no Realismo/Naturalismo. $\mathrm{O}$ autor acrescenta, ainda, um dado importante ao alegar que a temática do enfrentamento das forças do colonizador e as do colonizado, explorada no romance mexicano, “[...] se reiterará completamente no romance latino-americano posterior, quando já consolidado como um dos gêneros mais expressivos de nossa literatura.” (FLECK, 2017, p. 4748).

Xicoténcatl (1826) é apontada, também, como sendo a gênese da "Poética do “descobrimento"” em suas manifestações romanescas na América Hispânica, categoria que reúne uma miríade de leituras da saga empreendida pelo marinheiro Cristóvão Colombo, sendo expressões da lírica, do drama e do romance. Nela encontramos distintas formas de tratamento literário dado a Colombo e aos eventos protagonizados por ele, em 1492 e, dada sua extensão, também engloba a história da conquista e colonização do continente americano pela parcela europeia, a luta e a resistência pelas populações nativas e a formação dos povos mestiços originários da América.

Dado o volume e a recorrência dessas produções versadas em torno do mesmo tema, a ponto de serem reunidas na categoria da "Poética do "descobrimento", citamos alguns títulos circunscritas à modalidade crítica/desconstrucionista da literatura hispano-americana, como $E l$ arpa y la sombra (1979), de Carpentier, El mar de las lentejas (1979), de Benítez Rojo, Los perros del paraíso, de Abel Posse, Cristóbal Nonato (1987), de Carlos Fuentes como as narrativas mais expressivas do boom, consagradas pelo alto grau de experimentalismo linguístico e formal nelas presente pelo manejo e recorrência das estratégias e recursos escriturais desconstrucionistas. Do pós-boom, destacamos Crónica del Descubrimiento (1980), de Alejandro Paternain, Colombo de Terrarrubra (1994), de Mary Cruz, El Conquistador (2006), de Federico Andahazi e La tumba de Colón (2007), de Ruiz Montañez.

É, pois, Crónica del Descubrimiento (1980) que Fleck (2007) identifica como a manifestação de mais uma modalidade de romance histórico, a qual atribui a nomenclatura de romance histórico contemporâneo de mediação. A partir da análise da obra, constata que o escritor uruguaio concilia diferentes concepções que o gênero adquiriu ao longo de sua existência. Seguindo o princípio do romance histórico em solo hispano-americano, essa recente modalidade segue o intento de criticidade na forma de reler o passado, postura que vemos sustentada nas produções romanescas desde o início da década de 1930 com a obra de Ochoa, 


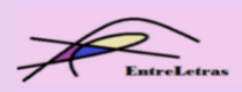

REVISTA ENTRELETRAS (ARAGUAÍNA), V. 12, N. 3, SET./DEZ. 2021 (ISSN 2179-3948 - ONLINE)

porém, por suas características, trata-se de uma escrita menos desafiadora aos leitores no que concerne ao tratamento dado à linguagem e à forma e cuja atenção daremos na sequência.

\section{Mediação e criticidade: o romance histórico contemporâneo de mediação - releituras da história pela ficção}

Nesse contexto de transformações, destacamos a terceira fase do gênero romance histórico, a crítica/mediadora. Essa modalidade mais recente no universo das produções híbridas de história e ficção foi estudada por Fleck $(2007$; 2017) e apresenta um conjunto considerável de obras que difere dos romances críticos/desconstrucionistas da segunda fase do gênero - estes ancorados no experimentalismo linguístico e formal típico do boom da literatura latino-americana -, cuja produção é recorrente desde o início de 1980 até os nossos dias.

Nela, identifica-se o abandono da intenção desconstrucionista, seja ela discursiva - com relação às versões hegemônicas - ou de personagens sacralizadas - elaboradas por meio de estratégias potenciais para isso -, utilizadas na fase crítica/desconstrucionista do novo romance histórico latino-americano e da metaficção historiográfica iniciada no boom.

Ademais, o estudioso pontua que o romance de mediação recria ficcionalmente um evento de modo distinto daquele realizado pelos cânones europeus, isto é, não prima por “[...] engrandecer heróis do passado como modelos para o presente e ensinar história ao leitor" (FLECK, 2017, p. 109). O que recupera, porém, é o intento de construção da verossimilhança em prol do estabelecimento de um pacto de leitura que considera plausíveis os eventos relidos no romance a partir de perspectivas periféricas ou marginalizadas, "[...] ancoradas em narradores-personagens antes vistos como secundários ou esquecidos pelo discurso historiográfico" (FLECK, 2017, p. 110).

Outro aspecto para o qual Fleck (2017) chama a atenção é para a presença de um foco narrativo geralmente centralizado e ex-cêntrico ou, então, que busca explorar visões "vistas de baixo", termo que emprega Jim Sharpe (2011) para se referir à atenção dada pelos historiadores às “[...] experiências históricas daqueles homens e mulheres, cuja existência é tão frequentemente ignorada, tacitamente aceita ou mencionada apenas de passagem na principal corrente da história.” (SHARPE, 2011, p. 41). Com base nisso, o romance de mediação apresenta, geralmente, a voz enunciadora do discurso fixada pelo foco único, que se manifesta, na maioria das vezes, de modo intradiegético e voz homo ou autodiegética.

As produções Crónica del descubrimiento (1980), do uruguaio Alejandro Paternain; Colombo de Terrarrubra (1994), da cubana Mary Cruz; El último crimen de Colón (2001), do 


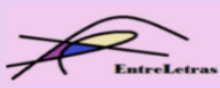

REVISTA ENTRELETRAS (ARAGUAÍNA), V. 12, N. 3, SET./DEZ. 2021 (ISSN 2179-3948 - ONLINE)

argentino Marcelo Leonardo Levinas, El Conquistador (2006), do argentino Federico Andahazi; A Caravela dos Insensatos: uma viagem pela renascença (2006), do brasileiro Paulo Novaes; Tríptico de la infamia (2014), do colombiano Pablo Montoya; Anacaona y Las Tormentas (1994), do também colombiano Luis Dario Bernal Pinilla; Anacaona, Golden Flower (2015), da haitiana Edwidge Danticat; Anacaona: la última princesa del Caribe (2017), da dominicana Jordi Díez Rojas são exemplos das narrativas que focam no papel do autóctone no processo da conquista e colonização ou que buscam contrastar a presença dos nativos com os vazios da história a que foram sucessivamente relegados, expressões que encontram acolhida entre escritores de diferentes nacionalidades.

É nesse sentido, portanto, que os traços que colocam as produções da "Poética do "descobrimento"” em uma relação dialógica e intertextual incidem no tratamento crítico e na singular releitura que propõem do material histórico acerca do "descobrimento" da América. A ausência de registros em relação à perspectiva do evento segundo o viés dessa parcela de sujeitos compõe, por exemplo, dentro dessa categoria, um dos eixos do tema do "descobrimento" e fornece ao romancista um amplo espaço de criação no cenário do romance histórico contemporâneo de mediação. A proposta de realização dessas releituras do passado aparece como resultado de um esforço que integra-se sob o seguinte entendimento:

[...] los escritores buscaron las vías para dar voz a esa memoria viva de sus pueblos y para exponer no sólo lo que significó para ellos la llegada de los españoles y los europeos, sino también lo que pensaban de aquella civilización que destruyó su mundo y su cultura. Y una de estas vías la encontraron en la novela histórica. (FERNÁNDEZ PRIETO, 2003, p. 156).

A ausência de registros escritos do primeiro encontro entre ameríndios e europeus segundo a perspectiva do autóctone, bem como o entendimento do que representou esse choque inicial expressa-se como um veio temático. Em torno disso, os escritores assinalam por meio de suas produções o interesse de retornar ao contexto fundacional da história americana, sob a égide europeia, para explorar outros vieses sobre o momento culminante do choque entre autóctones e europeus. Assim, em contraste com as narrativas perpetuadas pelos conquistadores, os escritores buscaram explorar outras histórias da conquista, com suas distintas versões e interpretações não contemplados pelo discurso histórico hegemônico.

A quebra de paradigmas que se opera nessas duas produções pode ser vista, embora não necessariamente, como um caminho aberto às alterações que começaram a surgir ainda na época do Romantismo na produção híbrida de história e ficção que passou, gradativamente, a alterar as características predominantes da escrita scottiana inicial. 


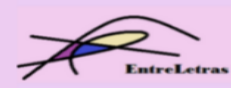

REVISTA ENTRELETRAS (ARAGUAÍNA), V. 12, N. 3, SET./DEZ. 2021 (ISSN 2179-3948 - ONLINE)

Assim, motivados a revisitar as possibilidades de ressignificação do passado disponíveis à ficção, embora o pós-boom tenha reivindicado uma escrita menos experimentalista - em termos linguísticos e formais - do que aquela consagrada no boom, as intenções críticas frente ao discurso eurocêntrico colonizador permanecem em pauta nas produções latino-americanas mais recentes sobre o "descobrimento" da América em vista das diferentes leituras citadas.

Essas são consideradas exemplares da terceira fase da trajetória do romance histórico: a crítica/mediadora, cujas obras representativas estabelecem um discurso paródico e intertextual com o Diário da viagem (1986), apresentando, para tal, a proposta de uma perspectiva do "descobrimento" ao revés, cujo resultado segue as intenções críticas descolonizadoras das obras da fase mais desconstrucionista da escrita híbrida de história e ficção.

Nas palavras de Fernández Prieto (2003, p. 168), essa ruptura na circularidade das narrativas históricas "[...] empuja el relato hacia los territorios de la sátira y de la parodia", o que, por efeito, passa pela degradação, rebaixamento e distorção dos modelos canônicos. A estratégia paródica aparece, nesse âmbito, como ato responsivo ativo na ressignificação dos fatos, dando ensejo à construção de relatos sobre o passado ao revés, pela forma como estabelecem relações com o discurso da história, não no sentido de legitimar a versão conhecida do passado, mas de questioná-la, ao reinventar os fatos ancorados em perspectivas distintas daquelas que já perpetraram uma possível versão pela escrita ao mesmo tempo em que eles são contestados.

Diante disso, os romancistas estão conscientes de que criar um espaço de expressão à voz dos silenciados não é uma tarefa fácil e que a ressignificação dos discursos fundacionais da nossa história enfrenta uma série de obstáculos. Muitos literatos, hoje, entendem, também, que dispor de outras perspectivas que não somente a do colonizador integra mais uma das vias para a descolonização do pensamento latino-americano, em especial.

\section{Considerações finais}

Em 1936, Walter Benjamin (1987) defendeu a tese, em $O$ narrador - considerações sobre a obra de Nikolai Leskov, de que a arte de narrar estaria em vias de extinção por efeito da gradativa incapacidade do sujeito moderno em narrar histórias, em intercambiar experiências.

A vivência do crítico literário em um período de devastação levou-o a associar o testemunho silencioso dos soldados que voltavam da guerra, mais pobres em experiência comunicável, à morte da própria narrativa. 


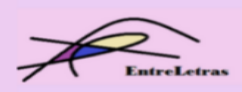

REVISTA ENTRELETRAS (ARAGUAÍNA), V. 12, N. 3, SET./DEZ. 2021 (ISSN 2179-3948 - ONLINE)

Contrariando, porém, os prognósticos do ensaísta alemão, concebidos em outro tempo e sob condições singulares, a investigação das transformações sofridas pelo conceito de narrador, com o advento da Modernidade, demonstram que, quando situamos essa reflexão no campo da literatura latino-americana, a questão ganha outra dimensão, uma vez que a dinâmica do romance, nesse contexto, parece mostrar o oposto do que postulava Benjamin: as novas sociedades emergentes da luta pela descolonização na América Latina sentem profunda necessidade de se narrar, de se autodemonstrar, pois, ao se narrarem elas se autoreconhecem, identificam-se e criam suas especificidades. Isso, também, está relacionado ao fato de sermos todos, neste continente, em boa parte, frutos de sociedades essencialmente orais, fato que nos diferencia daquelas sociedades sobre as quais refletia Benjamin

Como fruto das negociações das expressões culturais europeias com o hibridismo cultural e a mestiçagem étnica do contexto americano, operação debilitadora das noções de unidade, pureza e autenticidade cultivadas como modelo e referência, os romancistas latinoamericanos, com maturidade artística, articularam, dentro de seus produtos escriturais, um modo autônomo de contemplar os processos transculturais de manipulação da linguagem, composição literária e cosmovisão. Essa renovação, amalgamada, também, à relativização dos valores, estilos e parâmetros inculcados pela teoria literária ocidental, resulta como resposta do colonizado que assume uma posição estética própria, dando novos rumos às previsões de grandes críticos europeus.

Apesar de contarmos hoje com a ideia de que o colonialismo é condição passada, suas raízes ainda são profundas e extensas em muitas sociedades no nosso continente. No campo dos estudos pós-coloniais, no qual se busca compreender a extensão da cultura influenciada pelo processo imperial, recebe atenção também a literatura pós-colonial, entendida como toda a produção literária originada da experiência da colonização pelas potências europeias.

A desmistificação da constituição do cânone ocidental deve-se, em parte, ao desenvolvimento das literaturas pós-coloniais que se valeram de suas próprias vozes e do sincretismo para escreverem e expressarem os seus enfrentamentos contra o eurocentrismo e o imperialismo cultural. Nesse sentido, o novo romance histórico latino-americano e a metaficção historiográfica voltados às releituras do "descobrimento", conquista e colonização americana são produções exemplares.

Vemos, pois, que, desde meados do século passado até o presente, a escrita do romance histórico experimenta, no cenário literário latino-americano, um desenvolvimento extraordinário, evolução acompanhada por renovações técnicas e estilísticas e pela liberdade de 


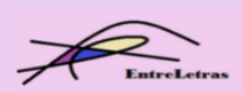

REVISTA ENTRELETRAS (ARAGUAÍNA), V. 12, N. 3, SET./DEZ. 2021 (ISSN 2179-3948 - ONLINE)

manejo do material histórico pelo romancista, aspectos que estabeleceram transformações profundas nesse gênero nascido no contexto europeu e, ao que tudo indica, parece seguir esse curso de renovações.

\section{Referências}

ANDAHAZI, F. El Conquistador. Buenos Aires: Planeta, 2006.

AÍNSA, F. El proceso de la nueva narrativa latinoamericana de la historia y la parodia. El Nacional, Caracas, p. 7-8, 17 dic. 1988.

AÍNSA, F. La nueva novela histórica latinoamericana. Plural, México, v. 240, p. 82- 85, 1991.

ANÓNIMO. Xicoténcatl. Prólogo, organização, estudo preliminar e notas de Antonio Castro Leal. [2. ed.]. p. 73-177. In: CASTRO LEAL, Antonio (Org.). La novela del México colonial. México: Aguilar, 1964.

BENJAMIN, W. Magia e técnica, arte e política. São Paulo: Brasiliense: 1987.

CARPENTIER, A. El arpa y la sombra. 3. ed. Madrid: Alianza Editorial, 2003.

CARPENTIER, A. El reino de este mundo. Madrid: Alianza Editorial, 2012.

DE LA FUENTE, J. L. La nueva novela hispanoamericana. Antología (1940-1970). Valladolid: Secretariado de Publicaciones e Intercambio Científico, 1996.

DEL POZO GONZÁLEZ, L. S. Malinche no espelho das traduções de Xicoténcatl (1826): [1999 - 2013]. 2017. 212 f. Dissertação (Mestrado em Letras) - Universidade Estadual do Oeste do Paraná - UNIOESTE, Cascavel, 2017

DONOSO, J. Historia personal del boom. Santiago de Chile: Andres Bello, 1987.

FLECK, G. F. O romance histórico contemporâneo de mediação: entre a tradição e o desconstrucionismo - leituras da história pela ficção: Curitiba: CRV, 2017.

MENDEZ, H. E. D. Nuestro Bolívar: da heroificação à humanização da sua figura na ficção. 2021.000 f. Dissertação (Mestrado em Letras). Universidade da Integração Latino-americanaUNILA, Foz do Iguaçu.

MENTON, S. La nueva novela histórica de la América Latina: 1979-1992. México: Fondo de Cultura Económica, 1993.

RODRÍGUEZ MONEGAL, E. La Nueva Novela Latinoamericana. Actas del III Congreso de la Asociación Internacional de Hispanistas: celebrado en México D.F. del 26-31 de agosto 1968.

PATERNAIN, A. Crónica del descubrimiento. Montevideo: Banda Oriental, 1980. 
POLLMAN, L. La nueva novela hispanoamericana. Un balance definitorio. Revista Chilena de Literatura, Chile, n. 34, p. 78-93, nov. 1989.

FERNÁNDEZ PRIETO, C. Historia y novela: poética de la novela histórica. 2. ed. Barañáin: EUNSA, 2003.

SANTIAGO, S. Uma literatura nos trópicos: ensaios sobre dependência cultural. 2. ed. Rio de Janeiro: Rocco, 2000.

SCHULMAN, I. A. El Modernismo Hispano-Americano. Buenos Aires: Centro Editor de América Latina, 1969.

TONET, T. P. Revolução Haitiana: da história às perspectivas ficcionais - El reino de este mundo (1949), de Carpentier, e La isla bajo el mar (2009), de Allende. 2018. 180 f. Dissertação (Mestrado em Letras) - Universidade Estadual do Oeste do Paraná - UNIOESTE, Cascavel, 2018 .

Recebido em 11 de novembro de 2021 Aceito em 03 de janeiro de 2022 